\title{
DIREITOS HUMANOS, ISLAM E XIISMO: A UNIVERSALIDADE DO CASO BRASILEIRO
}

Karina Arroyo

Doutoranda no Programa de Pós Graduação em Geografia da Universidade do Estado do Rio de Janeiro (PPGEO/UERJ).

kary_arc@yahoo.com.br

$\&$

Murilo Sebe Bon Meihy Professor de História Contemporânea do Instituto de História - Universidade Federal do Rio de Janeiro (IH-UFRJ). meihy1@yahoo.com.br 
resumo: Com a discussão contemporânea sobre a relatividade do que seriam os Direitos Humanos, em que pese a cultura a partir da qual se fala como ponto de partida, perde força a indagação acerca da legitimidade de um paradigma universal acerca desses Direitos, visto que a cultura, qualidade e atributo essencialmente humano é distinta conforme forem os grupos e suas diferentes temporalidades e espacialidades analisadas. Conceitos e juízos de valor delimitados sob uma ótica eurocentrada passam a ser deslegitimados, quando se entende tal problemática. Mesmo a ideia preliminar do binômio direitos/deveres admite uma construção categórica histórica e cultural de caráter fluídico e particular. Assim tomando o viés paradoxal dos Direitos Humanos que, embora humanos e universais não advogam em prol das minorias e segmentos inseridos em categorias mais amplas e generalizadas, podemos tratar da comunidade islâmica shi'a* ou duodecimana (ithna ashariyah) presente ao redor do globo. E nos limites deste artigo eleger como recorte a comunidade shi'a brasileira como foco de nossa reflexão através de um método crítico- analítico.

palavras-chave: Direitos Humanos, Islamismo, Eurocentrismo. abstract: With the contemporary discussion about the relativity of what human rights would be, in spite of the culture from which it is spoken as a starting point, the question about the legitimacy of a universal paradigm about these Rights is weakened, since culture, quality and essentially human attribute is different according to the groups and their different temporalities and analyzed spatiality. Concepts and value judgments delimited from a Eurocentric point of view become de-legitimized when this problem is understood. Even the preliminary idea of the binomial rights / duties admits a categorical historical and cultural construction of a fluid and particular character. Thus taking the paradoxical bias of Human Rights which, while human and universal do not advocate for minorities and segments within broader and more generalized categories, we can deal with the Shi'a or duodecimana (ithna ashariyah) Islamic community present around the globe. And within the limits of this article choose how to cut the Brazilian Shi'a community as the focus of our reflection through a criticalanalytical method.

keywords: Human Rights, Islam, Eurocentrism.

\footnotetext{
* Abreviação de shiaat Ali ou partidários de Ali, genro e primo de Muhammad, $4^{\circ}$ califa a governar após a morte do profeta do Islam. Seus seguidores acreditam na sucessão profética por linhagem, restringindo o poder islâmico ao núcleo familiar do Profeta a seus descendentes, enquanto a outra grande vertente do Islam, os sunitas, acreditam na sucessão por indicação a partir de certos critérios.
} 
direitos humanos: a quebra do monopólio ocidental

om a discussão contemporânea sobre a relatividade do que seriam os Direitos Humanos, em que pese a cultura a partir da qual se fala como ponto de partida, perde força a indagação acerca da legitimidade de um paradigma universal acerca desses Direitos, visto que a cultura, qualidade e atributo essencialmente humano é distinta tantos forem os grupos e suas diferentes temporalidades e espacialidades analisadas Conceitos e juízos de valor delimitados sob uma ótica eurocentrada passam a ser deslegitimados, quando se entende tal problemática. A creditando, como Max W eber, que o homem é um animal amarrado a teias de significados que ele mesmo teceu, considera-se a cultura como sendo essa teia complexa, de trama singular e histórica, todavia, ela não é objeto de uma ciência experimental à procura de leis, mas de uma ciência interpretativa, à procura de significado.

Por outro lado, ao analisar, de forma crítica, o processo de universalização dos Direitos Humanos, foi possível perceber que ao seu lado se desenvolveu uma multiplicação dos direitos do homem, com tutela cada vez mais específica do ser humano, muito embora, essa pluralidade na assistência não contempleas demandas nativas, e sim a compartimentalização dos grupos como agentes homogêneos dotados de interesses sociais e possibilidades de fruição comuns. Mesmo a ideia preliminar do binômio direitos/deveres admite uma construção categórica histórica e cultural de caráter fluídico e particular. A partir de então, podemos contemplar a

ARKOYO, K. e MEFH, M. S. B. Direitos Humanos. Islam e Xilismo: a universalidade do caso brasileiro

albuquerque: revista de historia. val. 9, n. 17, jan.-jul. de 2017. p. 191-205. 
discussão em tela, abordando o Islam como um corpo jurisprudencial, demograficamente expressivo capaz de erigir territórios a partir de suas práticas culturais instituídas 1 . Para que se compreenda a questão anteriormente levantada, acerca do paradoxo no qual os Direitos Humanos que, embora humanos e universais não advogam em prol das minorias esegmentos inseridos em categorias mais amplas e generalizadas, podemos tratar da comunidade islâmica shi'a2 ou duodecimana (ithna ashariyah) presente ao redor do globo. A inda assim, para um recorte mais eficaz, tomaremos a comunidade shi'a brasileira como exemplo através de um método crítico- analítico.

De acordo com trabalhos acadêmico-científicos mais recentes, o Islam tem crescido significativamentena Europajá como a segunda maior religião em número de adeptos (38.112.000) ea terceira nos Estados Unidos (2.454.000). N a A mérica Latina os muçulmanos totalizam 1085.000 adeptos. Já na Á frica, os muçulmanos somam 315.000.000 para uma população total de 778.484 .000 africanos. Na O ceania, somam 248.000 para uma população total de 29.460 .000 , mas é na Á sia que a população muçulmana é muito maior com 812.000.000 adeptos para uma população total de $3588.877 .000^{3}$. A diversidade entre os muçulmanos é tão grande quanto 0 desconhecimento que se tem delefora dos países islâmicos. $N$ ão háhomogeneidade nas práticas religiosas cotidianas. A essa pluralidade étnica, geográfica e cultural, ainda se acrescentam variadas maneiras de interpretar lei, normas e comportamentos, por isso, a ideia de que a religião islâmica teria uma essência que poderia ser reproduzida e reconhecida imediatamente é falsa, além de ser equivocada a ideia comumente difundida de que há deman das para direitos básicos de segurança, propriedade identidade para todos os muçulmanos de igual maneira independente das nações nas quais se encontram. Logo, a legitimidade, a forma e 0 significado, além dos efeitos práticos da implementação dos Direitos Humanos variam através das fronteiras culturais e em determinado tempo.

0 discurso de que os direitos primordiais derivam de cânones religiosos se sustenta, em grande medida, a partir do estabelecimento de uma linha divisória fundamental definida como Era Axial ${ }^{4}$, período que se enunciaram grandes princípios basilares, ainda que variáveis, de teor normativo que primavam por

\footnotetext{
1 BONNEMAISON. Joel. Culture and Space: Conceiving a new geography. London: LB Tauris e Co, 2005.

${ }^{2}$ Abreviação de shiaat Ali ou partidários de Ali, genro e primo de Muhammad, $4^{\circ}$ califa a governar após a morte do profeta do Islam. Seus seguidores acreditam na sucessão profética por linhagem, restringindo o poder islâmico ao núcleo familiar do Profeta a seus descendentes, enquanto a outra grande vertente do Islam, os sunitas, acreditam na sucessão por indicação a partir de certos critérios.

${ }^{3}$ BINICHESKI, Dilaine. Direitos Humanos Internacionais: Cultura Islâmica Frente às Relações de Gênero. Dissertação de Mestrado. Universidade Regional Integrada do Alto Uruguai e das Missões -URI Santo Angelo, RS, 2010, p. 113.

${ }^{4} \mathrm{O}$ filósofo alemão Karl Jaspers definiu a Era Axial (período que decorre entre o ano 800 a.C e o ano 200 a.C.) como a linha divisória mais profunda da História da humanidade, durante a qual apareceu a mesmo pensamento em três regiões do mundo: a China, a Índia e o ocidente.
} 
estabelecer diretrizes fundamentais para os gêneros de vida, em vigor até os dias de hoje. Compreende-se que foi nesse período, entre 600 e 800 a. C., que despontaram as grandes religiões confessionais: o budismo e 0 hinduísmo (Índia): 0 confucionismo e o taoismo (Extremo Oriente): o monotésmo (Oriente Médio); 0 racionalismo (Europa) e pensadores como Zaratustra na Pérsia, Buda na Índia, LaoTsé e Confúcio na China, linha de Pitágoras na Grécia e o Deutero-Isaías em Israel, elaboravam trabalhos metafísicos sobre os limites do essencialmente humano, os quais, a mais tarde, iriam influenciar na formação do pensamento acerca dos parâmetros da dignidade humana. Outro ponto fundamental no surgimento dos Direitos H umanos como al go desenvolvido politicamente, foi a própria consagração em torno da limitação do poder político, Comparato (2010), a respeito do assunto, nos diz que o reconhecimento de queas instituições de governo devem ser utilizada para o serviço dos governantes e não para o benefício pessoal, foi o primeiro passo decisivo na admissão da existência de direitos que, inerente à própria condição humana, devem ser reconhecidos por todos e não podem ser havidos como mera concessão dos que exercem o poder. Nesse sentido segundo este autor, deve-se reconhecer que a proto-história dos Direitos Humanos tem seu início nos séculos XI eX a. C., quando se institui, sob Davi, o reino unificado de Israel tendo por sua capital Jerusalém. 0 reino de Davi contrastou-se com o de outros regimes monárquicos do passado, quando estabeleceu, com mérito, pela primeira vez na história política da humanidade, a figura de um monarca que não se autoproclama Deus ou legislador, mas como um representante, um delegado do Deus único e foi visto pela literatura como uma nova organização política em que os governantes também são submetidos aos princípios e normas instituídas por uma autoridade superior.

De igual maneira, se nos atermos ao caso aqui analisado, sob a égide dos preceitos islâmicos e do Tratado dos Direitos, os Imames dos A hlul Bayt5, descendentes de Muhammad, seriam representantes ou líderes que deteriam 0 poder de infalibilidade na implementação das leis de caráter divino e, portanto, a princípio imutáveis. A inda que apresente uma estrutura normativa cristalizada, visto que deriva suas prescrições da imutabilidade al corânica, encontra na própria Jurisprudência (Usul ul Figh), um contraponto que expressa a possibilidade evidente de que reformas na prática e no entendimento de novos contextos são possíveis, pois o homem é apreendido dentro de suas limitações e fragil lidades.

Se por um lado, a jurisprudência islâmica histórica por ser entendida como a raiz de uma possibilidade de adequação da agenda de Direitos humanos a partir de valores herdados do Islam original, a leitura de que o Ocidente é a base de questões universalistas sobre o homem pode ser revista ou ampliada. A quebra do

\footnotetext{
${ }^{5}$ Em árabe é traduzido como: Gente da Casa. É um termo que se refere ao núcleo familiar do Profeta Muhammad, fundador do Islam. Composto por 5 membros principais: além do Profeta, a sua filha Fatimah Azzahrá, seu genro e primo Ali lbn Taleb, e os netos Hassan lbn Ali e Hussein lbn Ali.
}

AKROYO, K. e MEFHY, H. S. B. Direitos Humanos, Islam e Xilismo: a universalidade do caso brasileiro

albuquerque: revista de historia. val. 9, n. 17, jan.-jul. de 2017. p. 191-205. 
monopólio ocidental sobre a origem dos Direitos Humanos contemporâneos é um pressuposto aceitável que, mais do que a disputa pelo lugar primordial, comprova a total compatibilidade de uma agenda única e integrada que anula qualquer noção de que Islam e Ocidente são raízes culturais concorrentes. Mais do que apontar diferenças, toma-se como premissa a ideia de que o confronto inevitável entre experiências culturais distintas éuma construção discursiva que atende a interesses políticos específicos, mesmo porque, os chamados Direitos Humanos são desrespeitados de forma arbitrárias em todas as culturas, inclusive por Estados nacionais de ambas as partes do mundo aqui citadas.

Nesse contexto, ao se considerar a própria história da aceitação de valores universais institucionalizados sobre a condição humana no Ocidente, vê-se que além de relativamente recente, seu alicerce teórico depende de interpretações e vontade política, como no caso do Islam. Para tanto, cabe ressaltar que a noção universal de Direitos Humanos tem origem amplamente aceita no legado deixado pela perspectiva teórica do lluminismo, incluindo a concepção humanística e secularista da individualidade, da sociedade, e da organização política humanas ${ }^{6} .0$ reconhecimento do valor dessas questões está presente em documentos primordiais para a cultura ocidental, tais como a Declaração dos Direitos do H omem e do Cidadão, de 1789, e a própria Declaração dos Direitos Humanos das N ações Unidas, de 1948.

Não há dúvidas de que todos esses registros documentais sustentavam no período em que foram criados, motes prolixos propositalmente e politicamente instrumentalizados (e ainda o são). A ssim, por trás da manutenção desses valores encontra-se um elemento filosófico indiscutível tanto para o pensamento islâmico como para o que se reconhece como a herança mais transformadora do lluminismo: a crença incondicional na racionalidade humana. Um oportuno elemento que se mostrou presente a partir do século X VIII foi a busca do pensamento em usufruir e analisar seus próprios resultados, ou seja, somar às conquistas a presença de um progresso intelectual que passava a ser apresentado pela constante possibilidade de expansão do saber como uma força criadora originalmente singular. Nessa perspectiva, trata-se da razão como o resultado e o centro de dilatação da própria força criadora, produzindo decisivamente uma capacidade de alcance ao progresso intimamente relacionado à participação da razão definida pela sua unidade e imutabilidade, da mesma forma que os valores universais produzidos a partir do exercício dessa racionalidade. 0 bem e o mal seriam, respectivamente, as expressões máximas da aproximação ou do afastamento do homem em relação à razão e o

\footnotetext{
${ }^{6}$ Al- AZHMET, Aziz. Human Rights and Contemporaneity of Islam: a Matter of Dialogue? IN: The Universal in Human Rights: A Precondition for a Dialogue od Cultures - XV/th Conference of the Académie de la Latinité. 14-17 April 2007, amman, Jordan. Rio de Janeiro: Editora Universitária Candido Mendes, 2007, p. 66.
}

ARKOYO, K. e MEFH, M. S. B. Direitos Humanos. Islam e Xitismo: a universalidade do caso brasileiro

alouquerque: revista de historia. val. 9, n. 17, jan.-jul. de 2017. p. 191-205. 
progresso, tendo em vista que se essa é uma condição humana inerente, ela pode ser entendida e aceita por qualquer ser humano, sendo ele ocidental ou não.

Dentre os teóricos do século X VIII que discutiram a importância do livre exercício da razão e a construção de valores universais para a humanidade, encontra-se a figura do pensador prussiano Immanuel Kant. Suafilosofia tem como um de seus fundamentos mostrar que tanto o mal como o bem dependem da atuação do homem no mundo, mesmo que seja sabido que, em um primeiro momento, as ações humanas são contrárias à lei moral, e portanto, propensas ao mal. Dessa maneira, o homem não é outra coisa senão aquilo que se pretende ser. A identificação do mal em uma ação humana corresponde a uma opção do próprio homem em agir de uma maneira que poderia ser de outro modo, por se tratar de uma disposição natural intrínseca à natureza humana. Qual seja essa disposição natural, apenas a experiência do gênero humano pode tornála evidente. 0 homem, portanto, mesmo portador de uma razão prática, opta pela corrupção da lei moral que o leva a encaminhar a finalidade de suas ações à sua vontade particular, e a caracterização dessa escolha é sentida pelo conhecimento da ação humana através da experiência, ou seja, a partir de uma reflexão do caráter sensível pelas ações.

As especulações de Kant sobre a análise da experiência como modo de diferenciação da ação humana acaba por estabelecer uma definição de liberdade que garante à mesma a causalidade dos atos por ser responsável pela espontânea capacidade humana em agir de maneira inteligível. U ma crítica da experiência pode ser construída na medida em que se considere não somente ações em separado, mas sim, as atitudes do homem como um agente que transparece sua natureza humana através desses atos. $O$ que Kant propõe é uma investigação do homem como ser racional, sendo possível estabelecer essa procura por meio da apreciação das instituições criadas pelo homem, posto que asseguram a compreensão da experiência humana além do indivíduo. Marco A ntônio Zingano em sua obra Razão e História em Kant mostra a preocupação de Kant com o exame das instituições humanas através da pedagogia de sua época, fazendo da educação um objeto oportuno de análise da experiência humana?.

A partir dessas questões referentes a disposições naturais e propensões humanas, a leitura kantiana da experiência histórica deve ser admitida no contexto de criação dos valores universais da humanidade. A história, como objeto de uma reflexão filosófica, supera sua definição como um simples relato dos fatos e acontecimentos, designando-se, portanto, como uma análise que considera a existência de um conjunto de leis naturais universais. Trata-se de uma preleção sobre a organização dos acontecimentos na espécie humana segundo um princípio prático necessariamente cosmopolita, posto que se alimenta da universalidade da lei moral que integra a diversidade do desejo entre os homens. A proposta de reflexão

${ }^{7}$ ZINGANO, Marco Antônio. Razão e História em Kant. São Paulo: Editora Brasiliense, 1989, p. 223 e 224.

AROYO, K. e MEFY, M. S. B. Direitos Humanos, Islam e Xísmo: a universalidade do caso brasileiro

albuquerque: revista de historia. val. 9, n. 17, jan.-jul. de 2017, p. 191-205. 
histórica su stentada por Kant defende a constituição de uma "história do mundo" cosmopolita que submete os elementos empíricos vividos pela humanidade a um sistema racionalmente constituído; o que pode ser lido como um movimento original para a formação de um futuro conjunto de Direitos Humanos, independente das especificidades culturais de cada povo ${ }^{8}$.

N a obra de Kant intitulada Ideia de Uma História Universal de um Ponto de Vista Cosmopolita, tanto suas considerações iniciais quanto sua N ona Proposição (mesmo que haja outras discussões nessa proposição) estabelecem uma ponderação sobre a pertinência desse tema. Inicialmente, Kant apresenta através de uma metáfora queinvoca as inconstâncias atmosféricas, a existência de um curso natural "uniforme e ininterrupto" que serve como uma espécie de fio condutor da ação humana, mesmo que não se perceba a ação dessa força natural. Se não há como contar com a permanência de um propósito racional humano devido sua inclinação aos caprichos particulares, torna-se preciso atribuir a ação desse propósito à natureza, responsável por uma espécie de plano que conduza as criaturas a um sentido racionalmente constituído.A história é uma expressão do plano da natureza de gerar uma humanidade que esteja alinhada ao caminho da razão, dos val ores, e por que não, de Direitos Humanos universais. $O$ que se pode definir a partir dessas ideias é que há para Kant, um sentido último para a existência humana responsável pelo desenvolvimento das disposições morais que levam a humanidade à possibilidade de atingir o aperfeiçoamento da razão. A inda que na concepção islâmica essas disposições morais sejam dependentes da interpretação ou mediação de figuras moralmente corretas, como os Imames dos A hlul Bayt; no caso kantiano, de al guma forma, essa noção se consolida, já que só al cança o exercício livre da razão, aquele que a interpreta e a aplica a partir de uma moralidade específica. $O$ que se identifica como um elemento de distinção entre Islam e O cidente na construção de valores universais, portanto, não é a capacidade humana de, por meio da moral, atingir alguma forma de progresso, mas sim, a base dessa concepção de moral, que para o Islam é a religião, e para o lluminismo, a universalidade do pensamento secular.

Entretanto, al-Azhmet sugere uma definição mais ampla do Islam que reforça a sintonia entre seus intérpretes e o espírito universalista do Iluminismo, aqui representado e descrito pela obra de Immanuel Kant. Para al-A zhmet:

Moreover, Islam is not a culture, though like others religions, it does contain elements that might or not might be integrated into an extremely wide variety of societies, polities and cultures in very complex, real or phantasmatic ways; and what might be termed Islamic civilization is a bookish memory, like the Greekor

${ }^{8}$ ZINGANO, Marco Antônio. Razão e História em Kant. São Paulo: Editora Brasiliense, 1989, p. 259.

AriOYO, K. MEFHY, M. S. B. Direitos Humanos. Fslam e Xisiso: a universalidade do caso brasileiro

albuquerque: revista de historia. val. 9, n. 17, jan.-jul. de 2017. p. 191-205. 
the Roman, and has no determinate existence, no matter what reveries, nostal gias or aesthetic recollections it might generate. In any case. 'Islamic' civilization is a nominal category, which, in the way in which it is elicited today, concentrates on religious elements and excludes others, which were - arguably - of greater historical importance. ${ }^{10}$

"Islam", portanto, deve ser tomado da mesma forma com o "Iluminismo" é definido na história da civilização ocidental: como uma experiência temporal humana que não se limita a uma única dimensão do conceito, e porta em si um conjunto de normas que se alinham a preceitos tomados na contemporaneidade como universais e dotados de um legado que transcende o próprio conceito.A ssim, seus valores recaem sobre a comunidade de fiéis e a todas as demais formas de organização humana que se relacionaram com seus pressupostos, sejam elas regras de comportamento, princípios filosóficos gerais, ou mesmo formas concebidas de instituições sociais e políticas presentes na história.

Por essa razão, Kant também se preocupa com o peso da racionalidade e dos valores universais do lluminismo nos sistemas humanos. 0 problema da compleição de uma instituição "... que administre universalmente o direito" está exposta na Quinta Proposição de Ideia de Uma História Universal de um Ponto de Vista Cosmopolita. $O$ texto ressalta a ação imperativa da natureza em querer que o gênero humano esteja submetido a uma espécie de "poder irresistível" expresso pela "constituição civil perfeitamente justa". A tarefa da natureza de criar as circunstâncias necessárias para os homens desenvolverem suas disposições naturais encontra-se realizada a partir da constituição civil perfeita, que deve garantir as condições necessárias ao desenvolvimento da lei moral entre os homens. Essa constituição civil perfeita, resultado da necessidade do homem em abrir mão de sua liberdade sem vínculos, admite a instauração de um estado repressivo baseado em uma definição de direito como uma "faculdade de obrigar"; como uma determinação coercitiva porque impõe a ação pelo dever¹.

\footnotetext{
9 “Além disso, o Islã não é uma cultura, embora, como outras religiões, contenha elementos que possam ou não ser integrados em uma variedade extremamente ampla de sociedades, políticas e culturas de formas muito complexas, reais ou fantasmagóricas; e o que pode ser chamado de civilização islâmica é uma memória esparsa, como a grega ou a romana, e não tem existência determinada, não importa quais fantasias, nostalgias ou lembranças estéticas possam gerar. Em qualquer caso, a civilização "islâmica" é uma categoria nominal, que, na forma como ela é suscitada hoje, concentra-se em elementos religiosos e exclui outros, que tinham - sem dúvida - maior importância histórica".

${ }^{10}$ Al- AZHMET, Aziz. Human Rights and Contemporaneity of Islam: a Matter of Dialogue? IN: The Universal in Human Rights: A Precondition for a Dialogue od Cultures - XV/th Conference of the Académie de la Latinité. 14-17 April 2007, amman, Jordan. Rio de Janeiro: Editora Universitária Candido Mendes, 2007, p. 70 e 71.

11 BOBBIO, Norberto. Direito e Estado no Pensamento de Emanuel Kant. Brasília: Editora Universidade de Brasília, 1984, p. 77.
} 
A questão da constituição civil perfeita em Kant, à medida que versa sobre a aceitação de normas repressivas sobre os seres humanos com o intuito de garantir direitos universais, não apenas institui uma visão abrangente do caráter humano, como também aborda a promessa de que a anulação das diferenças culturais pode ser superada pelo estabelecimento de um ambiente geral alicerçado em valores amplos que, uma vez respeitados, permitiriam a formação de uma atmosfera internacional pacífica e ordeira. N orberto Bobbio ressalta que Kant ao elaborar seu ensaio denominado Sobre a Paz Perpétua, tenta trazer ao debate filosófico o problema da paz internacional e uma análise das relações políticas a partir de seu sistema de desenvolvimento do progresso humano pela razão e pela lei ${ }^{12}$.

U m dos elementos ressaltados em Sobre a Paz Perpétuapara esse fim referese à proposta de que o direito internacional deve alicerçar-se em uma federação de Estados livres. N esse ponto, Bobbio sustenta a existência de um pacifismo jurídico em Kant que defendea formação de uma federação de Estados responsável por uma distribuição equitativa de direitos mais complexa do que um simples tratado de paz entre seus membros. Dessa forma (e como terceiro e última ideia central vista por Bobbio), a federação produz um direito cosmopolita distinto do direito internacional, posto que ao invés de tratar das relações entre os Estados, o direito cosmopolita regula as relações entre um Estado eàqueles que não o integram diretamente. Kant tenta construir um projeto jurídico que alargue a sociabilidade entre os homens, independente de sua condição nacional ${ }^{13}$.

Se as considerações sobre o caráter universal das ideias iluministas é algo genérico que se estende a todos, independente de suas filiações religiosas, culturais ou nacionais, por que ao se tratar do Islam e de seu legado histórico há certo limite para o reconhecimento de val ores universais que não se limitam aos muçulmanos? Por que a necessidade de se defender a total compatibilidade do Islam com aquilo que se chama hoje em dia de "Direitos Humanos"?

\section{o islam atual e os direitos humanos: o caso do islam shi'a}

O que se questiona, então, é como extrair uma dinâmica normativa e de garantia de Direitos que se adapte e corresponda aos atuais problemas sofridos pelas diversas comunidades acerca da diáspora, fluxos migratórios e complexas questões de gênero na contemporaneidade, tanto no chamado "Mundo Islâmico" com no Ocidente. A Reforma religiosa islâmica torna-se uma responsabilidade coletiva quando entendida como uma soma de esforços contínuos individuais capacitados

12 BOBBIO, Norberto. Direito e Estado no Pensamento de Emanuel Kant. Brasília: Editora Universidade de Brasília, 1984, p. 157

${ }^{13}$ BOBBIO, Norberto. Direito e Estado no Pensamento de Emanuel Kant. Brasília: Editora Universidade de Brasília, 1984, p. 164.

ArioYo, K. e MEFHY, H. S. B. Direitos Humanos, Islam e Xisiso: a universalidade do caso brasileiro

albuquerque: revista de historia. val. 9, n. 17, jan.-jul. de 2017. p. 191-205. 
tecnicamente para tal atividade, admitindo que haja alteridades naturais e perenes entre homens e contextos culturais e que não devem ser admitidas como vicissitudes, já que são parte inerente dessa prática que visa o auto aperfeiçoamento e o bem estar social, conhecida, no Islam, como litihad. Portanto, mais do que interessante observar esses princípios basilares e estudálos é imperioso compreender sua aplicabilidade em uma sociedade atual, profundamente dinâmica, contingencial e instável. Tais características gerais são próprias do Ocidente altamente globalizado em toda sua fluidez e volatilidade onde o Islam grassa sua semiografia cada vez mais, para além das outras nações no Oriente Médio e na Á sia que, ainda que sejam islâmicas, se amalgamam em diversas vertentes que se complementam e se distanciam na variedade de questões que perpassam o $\operatorname{Din}^{14}$.

Revisar e adaptar exige um esforço intelectual dos sábios jurisconsultos ou mujtahid, no entanto, quaisquer releituras nas práticas cotidianas acerca de variados assuntos não devem ser substituídas pela mecanicidade de lidar com o estabelecido, mas devem sempreimpor à razão sua total compreensão,e, portanto,éum exercício intelectual científico direcionado para a teologia, é exercida por sábios jurisconsultos como reforma contínua e vitalícia na resolu ção de todo e qualquer assunto atinente ao homem.

A partir disso, compreende-se quehámovimentos reivindicatórios distintos para a consecução dos Direitos Humanos a partir de óticas islâmicas diversas. A título de exemplo, no Islam shi'a de subdivisão alauita, Omran ${ }^{15}$ nos diz que "A identidade dos alauitas no Brasil se constrói tendo a palavra religiosa associada ao sentimento de pertencimento a uma pátria, no caso a Síria, já que se originam das montanhas do país árabe e com ele mantêm fortes vínculos."Tal extrato corrobora a definição da geografia cultural francófona atribuindo à cultura a capacidade de criar territórios, ultrapassando o sentimento topofílico com a terra, a ligação com elementos característicos da paisagem (montanhas) e materializando-se na prática religiosa. A brange todos os aspectos da vida, trazendo a ideia de código de conduta integral, evidenciando elementos de fé, estética, agência e controle. Essa cultura característica de determinado ramo do Islam shi'a mostra uma ramificação advinda de uma segunda ramificação, complexificando as relações dentro do Islam. Sendo assim, mais adiante, pode-se constatar que tais divisões sociopolíticas acarretaram perseguições que só cessaram quando alcançaram representatividade no poder presidencial só no século XX com H afez AI A ssad, o primeiro presidente alauita. A inda de acordo com Omran 16: 'O grupo religioso foi condenado por clérigos do islã

\footnotetext{
${ }^{14}$ Modo de vida islâmico.

15 OMRAN, Muna. O discurso religioso da preservação identitária nas comunidades muçulmanas alauitas do Brasil. Revista Espaço \& Cultura, n.37, v.1, Rio de Janeiro, 2015, p. 55.

${ }^{16}$ OMRAN, Muna. 0 discurso religioso da preservação identitária nas comunidades muçulmanas alauitas do Brasil. Revista Espaço \& Cultura, n.37, v.1, Rio de Janeiro, 2015, p. 61.
}

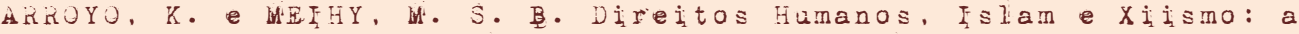
universalidade do caso brasileiro

albuquerque: revista de historia. val. 9, n. 17, jan.-jul. de 2017. p. 191-205. 
sunita, como Ibn Taymiyya, que, em uma fatwa ${ }^{17}$ instaurou ajihad contra os al auitas o que provocou, por muito tempo, intensa perseguição e preconceito em relação ao grupo." No Islam shi'a e em suas vertentes, para além das compilações de hadices ${ }^{18}$ uma das fontes do Direito islâmico, há obras escritas pelos primeiros I mames tanto como compendio tanto como uma compilação de comentários críticos acerca dos Direitos fundamentais. 0 mais conhecido foi definido como:

Colocamos em vossas mãos o livro: 0 Tratado dos direitos pelo quarto Imam dos A hlul Bait (A S), o Imam Ali ibnol Hussein ibn Ali ibn abi Taleb "Zainol A bedin"(A S.).Podemos dizer queesta obra é a mais grandiosa e o mais importante documento escrito sobre os direitos humanos e que representa a gran diosidade da legislação islâmica. ${ }^{19}$

$\mathrm{Na}$ modernidade outros documentos foram escritos buscando a representatividade de seus grupos e inserindo-os no final do século $X X$, preparando-os para as novas demandas de um novo século despontando no porvir e estabelecendo princípios e diretrizes autônomas para a elaboração desses documentos. A Declaração Islâmica U niversal dos Direitos Humanos proclamada pelo Conselho Islâmico da Europa, na cidade de Paris em 1981, baseou-se no A Icorão e na Sunnah e foi compilada por estudiosos, juristas e representantes muçulmanos das escolas de pensamento ${ }^{20}$. 0 segundo documento fundamental proclamado pelo Conselho Islâmico para marcar o inicio do $15^{\circ}$ século da Era Islâmica, sendo 0 primeiro a Declaração Islâmica Universal ${ }^{21}$ proclamada na Conferência Internacional sobre o Profeta Muhammad e sua Mensagem, ocorrida em Londres, no período de 12 a 15 de abril de 1980. Logo depois, a Carta de Banjul foi A provada pela Conferência M inisterial da organização da U nidadeA fricana (OUA ) em Banjul, Gâmbia, em janeiro de 1981, e adotada pela X VIII A ssembleia dos Chefes de Estado e Governo da Organização da Unidade A fricana (OU A) em N airóbi, Quênia, em 27 de julho de 1981, mostrando a emergência das vozes dissonantes, convictas e ativas contra um parâmetro universal de direitos. Neste ínterim, entre as primeiras movimentações na década de 80 e a atualidade, ampliamos o panorama estimativo

\footnotetext{
17 Decreto.

18 Ditos e atos do Profeta Muhammad de caráter normativo. Escolas de pensamento ou escolas de jurisprudência são métodos interpretativos acerca das fontes do Direito Islâmico.

19 KHAZRAJI, Taleb. O Tratado dos Direitos: Por Ali Ibnol Hussein (A.S). São Paulo: Arresala, 2005, p. 14.

20 Existem inúmeras, no entanto, dentre as mais expoentes podemos citar 5 , sendo 4 sunitas e 1 xiita respectivamente: hanafi, hanbali, maliki, shafi'i e jaffariyyah

21 Disponível em: http://www.arresala.org.br/biblioteca/declaracao-islamicadosdireitoshumanosuniversais.
}

ARROYO, K. MEFY, M. S. B. Direitos Humanos, Fslam e Xiismo: a universalidade do caso brasileiro

albuquerque: revista de historia. val. 9, n. 17, jan.-jul. de 2017, p. 191-205. 
acerca da vertenteislâmica shi'a através do Pew Research Center Forum on Religion \& Public Life;

\begin{abstract}
An overwhelming majority of Muslims are Sunnis, while an estimated $10-13 \%$ are Shias. This report estimates that there are between 154 million and 200 million Shia Muslims in the world today. Between I 16 million and 147 million Shias live in A sia, representing about three-quarters of the world's Shia population (note that Iran is included in the A sia-Pacific region). M eanwhile, nearly a quarter of the world's Shias 6 million to 44 million) live in the Middle East-N orth A frica.22
\end{abstract}

Os shi'as e suas demais vertentes estão entre os segmentos religiosos mais perseguidos e coagidos ao redor do globo. De acordo com a agência Shia Rights W atch", fonte fidedigna para as N ações Unidas em W ashington, EUA, os números atualizados de junho de 2017 corroboram tais afirmativas, mostrando um pequeno recorte nos países do Oriente Médio e Á sia em incidentes anti shi'a resultando em mortes: A rábia Sau dita (3), A feganistão (11), Paquistão (62), I rã (11) e Iraque (72).

Quando falamos acerca da comunidade shi'a no Brasil, estamos falando de uma comunidade majoritariamente oriunda de um fluxo migratório sírio-libanês pós 1890 para o sul e sudeste do país e, principalmente, na pós guerra civil libanesa (1975-1990). Dentre a população de maioria shi'a, os iranianos não representam uma migração considerável, visto que há um caráter de transitoriedade no fluxo de pessoas entre Brasil e Irã que se dá muito mais com a finalidade de cooperação acadêmica entre as universidades nacionais e iranianas.

Neste sentido, surge no Rio de Janeiro, o Observatório $X$ iita de Direitos Humanos (OX DIH), criado em 2016, tendo como sede o Centro Cultural Imam Hussein. O Observatório é uma entidade de pesquisa não-governamental sem fins lucrativos formada por um grupo multidisciplinar com sede no Rio de Janeiro, despontando como a primeira organização independente no Brasil dedicada a proteger os direitos dos muçulmanos shi'as em território nacional. O OXDIH alcança seus objetivos por meio de investigações estratégicas apoiadas por uma advocacia direcionada, a fim de levar a cabo ações de prevenção e combate à intolerância e levantamento estatístico dessas ações discriminatórias. Com base nessa atividade e em outras desse teor e importância, desenvolvidas pelo Centro

\footnotetext{
22 Tradução: A maioria esmagadora dos muçulmanos são sunitas, enquanto estima-se que 10 a $13 \%$ são xiitas. Este relatório estima que há entre 154 milhões e 200 milhões de muçulmanos xiitas no mundo de hoje. Entre 116 milhões e 147 milhões de xiitas vivem na Ásia, representando cerca de três quartos da população xiita mundial (note que o Irã está incluído na região Ásia-Pacifico). Enquanto isso, cerca de um quarto dos Shi'as do mundo (36 milhões a 44 milhões) vivem no oriente Médio África do Norte. Disponivel em http://www.pewforumorg/2009/10/07/mapping-the-global-muslim-population/\#sunni-and-shiaations. Acesso em: 12/07/2017
}

\footnotetext{
ARZYY, K. MEFY, M. S. B. Direitos Humanos, Islam e Xiismo: a universalidade do caso brasileiro

albuquerque: revista de historia. val. 9, n. 17, jan.-jul. de 2017, p. $191-205$.
} 
Cultural e parceiros, o OXDIH passa então a figurar como uma organização reconhecida pelo Comitê de Combate à Intolerância Religiosa do Estado do Rio de J aneiro (CCIR), um dos principais comitês de atuação social contra a discriminação e listado na página do Ministério Publico do Estado do Rio de J aneiro (MPRJ $)^{23}$

Para alcançar esses fins, o observatório investiga violações contra as comunidades shi'as, para aumentar a consciência e combater a discriminação por quaisquer meios. A principal missão proposta é a de "promover a mudança necessária através de pesquisas acadêmicas e publicações, com submissão de relatórios e artigos às esferas governamentais e organizações internacionais. A lém disso, o OX DIH monitora continuamente os meios de comunicação para garantir a cobertura das violações dos direitos shi'as'(adaptado). ${ }^{24}$

Dentro desse contexto permanentemente iminente de coação, a organização Shia Rights $W$ atch elegeu 0 dia 12 de junho como o Dia Internacional dos muçulmanos shi'as em lembrança ao massacre ocorrido em Camp Speicher em 2014, quando 1566 Shi'as, cadetes da Força A érea I raquiana sofreram um ataque do Grupo Terrorista ISIS (Islamic State of Iraq and Syria) ou Daesh na cidade de Tikrit, tornando esta ofensiva a mais sectária e letal contra os shias desde o governo do presidente Saddam H ussein. A li H ussein Kadhim, o único sobrevivente conhecido do ataque fal ou sobre a decisão de fingir-se de morto durante os tiroteios, esperando até a noite cair, quando fez a sua fuga. 0 testemunho de Kadhim, tornou claro que este ataque foi amplamente ignorado pela Comunidade Internacional e mídia, tornando as questões atinentes aos Direitos H umanos deveras moralmente seletiva.

Com relação aos Direitos Humanos no Ocidente ou no Mundo islâmico, o uso político e instrumentalizado de sua retórica continua sendo um desafio universal. $N$ as palavras de al-A zhmet:

The etiquete of dialogue needs to be calibrated, and brought into connection with the etiquete of critique, including self-etiquete beyond the apologetic requirements, and with the universality of Human Rights proposed as a pre-condition for dialogue. And, it would seem advisable to note that the dialogue, or rather the debate, cannot countenance an 'inside' and 'outside'; it is - and has been for two centuries - internal to the A rab world, and involves not only deliberative interlocutors, but social forces, cultures,

23 Disponível em: http://www.mprj.mp.br/conheca-o-mpri/areas-de-atuacao/direitos-humanosconselhos-e-comissoes

${ }^{24}$ Disponível em: http://www.centroimamhussein.com/oxdih

ARKOY, K. MefHY, M. S. B. Direitos Humanos. Islam e Xiismo: a universalidade do caso brasileiro

albuquerque: revista de historia. val. 9, n. 17, jan.-jul. de 2017, p. $191-205$. 
political structures and entities, in contestations that are not entirely dialogical. 2526

\begin{abstract}
25 “A etiquete do diálogo precisa ser calibrada e trazida em conexão com a etiquete da crítica, incluindo a auto-etiqueta além dos requisitos da apologética, e com a universalidade dos Direitos Humanos proposta como pré-condição para o diálogo. E, parece aconselhável observar que o diálogo, ou melhor, o debate, não pode tolerar um "interior" e "exterior"; É - e tem sido durante dois séculos - interno ao mundo árabe e envolve não só interlocutores deliberativos, mas forças sociais, culturas, estruturas políticas e entidades, em contestações que não são inteiramente dialógicas".
\end{abstract}

${ }^{26}$ Al- AZHMET, Aziz. Human Rights and Contemporaneity of Islam: a Matter of Dialogue? IN: The Universal in Human Rights: A Precondition for a Dialogue od Cultures - XV/th Conference of the Académie de la Latinité. 14-17 April 2007, amman, Jordan. Rio de Janeiro: Editora Universitária Candido Mendes, 2007, p. 81. 